\title{
Metáforas: Notas Sobre Su Producción Y Significado Cultural Y Político
}

\author{
Ricardo Angel Minetti
}

Magíster en Ciencias Sociales Universidad Nacional del Litoral, Argentina

Doi: 10.19044/esj.2018.v14n5p241 URL:http://dx.doi.org/10.19044/esj.2018.v14n5p241

\begin{abstract}
The purpose of this text is to outline the relevance of the study of metaphors as a valid political culture resource for approaching the study of culture and politics, since it puts at stake, in its configuration, symbolic materials produced by society generally historically, on diverse aspects of reality. It is therefore proposed to analyze metaphors belonging to the heritage of Argentina's and Latin America political history to illustrate and apply a "rule of interpretation" that accounts for its contents and modalities of elaboration.
\end{abstract}

Keywords: Metaphors; politics; culture; history; meaning

\section{Resumen}

Este texto plantea la pertinencia del estudio de las metáforas como un recurso válido para el abordaje de la cultura y la política, toda vez que ponen en juego, en su configuración, los materiales simbólicos elaborados por la sociedad, generalmente de manera histórica, sobre los más diversos aspectos de su realidad. Se propone en consecuencia analizar metáforas pertenecientes al acervo de la historia política argentina y latinoamericana para ilustrar y aplicar un "régimen de interpretación" que dé cuenta de sus contenidos y modalidades de elaboración.

Palabras clave: Metáforas; cultura; política; historia; significado

\section{Introducción}

Expresar nuestro conocimiento de y sobre las cosas: un propósito tan vasto, tan humano y tan antiguo que dan cuenta de él el lenguaje en todas sus formas y soportes, de los que nos valemos para dar a conocer saberes y sentidos.

Sin embargo, en correlación temporal exacta con la antigüedad de ese cometido, se halla presente la dificultad de hacer comunicables ciertas ideas 
dentro de los límites que marca la material o el aspecto más exteriormente perceptible de las cosas que afectan la experiencia humana.

Las metáforas tienen que ver con lo enunciado en los párrafos anteriores, en la medida en que a) sin dudas se presentan como un recurso del lenguaje, y b) permiten expresar atributos a los objetos a los que se aplican cuyo significado procede la configuración cultural de los grupos que las crean.

Dotadas de un procedimiento constructivo propio, parecen escapar a las reglas de la lógica y de cualquier método científico. En la medida que se generan y circulan en los circuitos más cotidianos de la comunicación, su naturaleza imaginativa y asociativa no despierta mayores reservas.

Sin embargo, o gracias a ello, han demostrado, a lo largo de la historia, una extraordinaria capacidad para inmiscuirse no sólo en el vocabulario formalizado y científico, sino también para calar en los supuestos con los que procede la ciencia para explicar y actuar sobre el mundo.

Este abordaje exploratorio del mundo de las metáforas (en particular referencia a las del universo político), pretende reivindicar e ilustrar estos recursos quizá menos reconocidos para comprender los sustratos de significado que subyacen y se expresan en las configuraciones culturales de distintos medios sociales, los cuales alimentan la creación de metáforas, que pueden quedar circunscriptas en el ámbito de una singularidad cultural, o adquirir una dimensión universal.

La producción académica específicamente referida a las metáforas, en el sentido que aquí interesa, no es muy abundante, lo cual se halla en sintonía con el papel de recurso auxiliar que se les asigna para explicar los fenómenos sociales (y que parece reforzar el poder subrepticio que desempeñan en la cultura). Resulta de interés destacar los trabajos de Lakoff y Johnson, Metaphors we live by (1980), en el cual los autores abordan de manera sistemática la construcción de diversos tipos de metáforas, enfatizando en su papel como elementos de comunicación cotidiana y científica, y, por otra parte, de Emmanuel Lizcano, Metáforas que nos piensan (2006), que se destaca por su sentido crítico y el escudriñamiento cultural en el análisis de las metáforas. Ambas obras están recuperadas en este trabajo.

\section{Metáforas y/en la cultura}

La metáfora pertenece de manera incontestable a los mundos de la literatura, la retórica, la lengua, y sin duda ha estado presente en ellos desde antiguo, como lo atestiguan sobradamente numerosos textos religiosos $\mathrm{y}$ poéticos.

Sin embargo, toda vez que efectuamos una aproximación a lo que las metáforas significan por sí mismas (y que las distingue de otras formas de la retórica), hallamos de inmediato que desbordan esa circunscripción, y se presentan como un procedimiento para hacer inteligible las cosas del mundo 
de manera creativa. Conviene inscribir a las metáforas, entonces, desde el principio, en el mundo de la cultura, de allí que, más allá de la existencia de potentes metáforas universales ${ }^{16}$, cada sociedad tenga sus propias metáforas y su propio estilo de construirlas. A decir verdad, al menos como lo ilustra al menos el caso de las religiones, puede decirse que es en estos contextos "situados" donde estas se originan para luego universalizarse.

La mención a la cultura resulta necesaria, en la medida en que las actividades de simbolización, que alcanzan prácticamente todos los aspectos de la vida humana asociada, incluyen la "actividad metafórica" en tanto que permite asignar diversos significados a sus objetos, personas, acontecimientos ${ }^{17}$. Es decir, se nutren del sustrato ideacional de la cultura, para procesar y expresar de manera condensada y alternativa lo que reviste una relevancia particular para un grupo social, escapando a la lógica representativa "realista" de la literalidad.

La metáfora tiene mucho qu e ver con el mundo de los símbolos, no solo porque representan o sustituyen algo ausente, sino porque vehiculiza un régimen de interpretación, en el cual interactúa el campo del cual la metáfora es extraída, y aquel en el que es aplicada a objetos a los que no corresponden de manera lógica.

La expresión de "régimen de interpretación", pretende dar cuenta de las distintas posibilidades que se abren para la atribución de significados, a partir de las propiedades puestas en juego de manera relacional, entre dos o más términos implicados en la metáfora. El escenario se complejiza si aceptamos (como de hecho ocurre) la combinación de las alternativas sociales y subjetivas para esas atribuciones.

Otra aclaración pertinente: en este escrito se intentan bosquejar algunos esquemas que den cuenta de los componentes, el funcionamiento y los efectos de ciertas metáforas. Es sabido como muchas de ellas dieron origen a herramientas cognitivas muy elaboradas del conocimiento científico, como

\footnotetext{
${ }^{16}$ Las religiones universales han sido prolíficas en este punto. El antropólogo Marco Aime entiende, al parecer según la lógica del materialismo histórico, que ninguno de los credos monoteístas propone el vegetarianismo como práctica alimentaria porque se desarrollaron en zonas áridas y semidesiertas donde el cultivo de vegetales era muy difícil, de allí que "muchas de sus metáforas relativas a los seres humanos son de carácter animal: Jesús visto como el Buen Pastor, y sus fieles como un rebaño" $(2015,57)$. Otro tanto ocurre con el "Cordero de Dios", metáfora según la cual Dios Hijo asume el sacrificio de la cruz por la salvación del mundo. El budismo, al haberse desarrollado en ambientes tropicales, promueve el vegetarianismo y sus metáforas relativas al hombre son extraídas del reino vegetal: "tallo entre los tallos, caña entre las cañas" (57).

${ }^{17}$ La relación entre metáforas, cultura y oralidad es reconocida y puesta de relieve por Lakoff y Johnson (1980), quienes dan análoga importancia a su capacidad para crear "realidades nuevas", no sujetas a patrones de relacionamiento establecidos.
} 
por ejemplo lo ilustra el caso de la "raíz cuadrada"18, y de muchas otras expresiones ${ }^{19}$ que la ciencia experimental iría poniendo en tela de juicio en el transcurso de su desarrollo, fundamentalmente porque se basaban en ideas equivocadas acerca de los fenómenos y las infectaban transfiriéndoles propiedades y comportamientos propios de ellas, pero no del objeto al cual se aplicaban.

Aquí no interesa desterrarlas de las idola o los obstáculos epistemológicos que entorpecen la tarea de la ciencia, portadoras del germen del error y la falsedad, sino hacerlas objeto de atención intelectual por lo que pueden poner en evidencia, lo que revelan (no siempre sorpresivamente, por supuesto) acerca de una sociedad en relación con su medio y su época.

Cabe pensar, entonces, que al detentar la sociedad la capacidad de generar sus propios mecanismos de creación e interpretación de metáforas, en consecuencia, los diferentes grupos las poseen a la manera de atributos propios y singulares, como se dijo precedentemente.

Esa actividad que en principio cabe situar en el orden simbólico, también se desenvuelve en la esfera del poder y la política. Prácticamente no se conocen comunidades humanas con cierta continuidad en el tiempo sin un ordenamiento de las relaciones de autoridad, de lo cual resulta que la metaforización también se extiende a ellas.

¿En qué pueden, entonces, contribuir las metáforas con el estudio de la política o, más específicamente, la cultura política? Esta pregunta debe ser respondida en función de las propiedades e incluso los efectos que ellas presentan como recurso comunicativo. Porque si, como casi todo constructo cultural, son susceptibles de ser interpretadas de más de una manera, quien las

${ }^{18}$ E. Lizcano se detiene en el análisis de esta curiosa expresión: "Para los imaginarios griego, romano y medieval, imaginarios agrícolas y animistas en buena medida, el número, como tantas otras cosas, se percibía, efectivamente, como si fuera una planta (...) Hemos perdido la conciencia y el sustrato imaginario del símil que hacía vero-símil la metáfora, y lo que era vero-símil se nos ha quedado en simple 'vero', verdad pura y simple, es decir, purificada y simplificada del magma imaginario del que emergió" $(2006,62)$. En este caso se transfiere la idea de potencia generativa de la raíz de una planta, asociada a la operación aritmética de la multiplicación, a la figura del cuadrado, cuya superficie resulta justamente de la multiplicar dos lados.

${ }^{19}$ En esta tónica, Gastón Bachelard dedica todo un capítulo de La formación del espiritu científico a desmontar los efectos de la asociación con la esponja (2013), para explicar diferentes fenómenos naturales. "La tierra es una esponja y el receptáculo de los demás elementos" (91), "la sangre es una especie de esponja impregnada de fuego" (92), son algunas de esas metáforas utilizadas en particular en el lenguaje científico -si cabe el término- del siglo XVIII, en las cuales hay una transferencia de la idea de porosidad, receptividad, compresión, etc., hacia el objeto que pretende estudiarse, y sustituyendo la explicación de una causa desconocida en virtud de la (supuesta) transparencia de la metáfora. 
utiliza conoce cuáles son los sentidos que deben (o deberían) aparecer resaltados en el contexto de su uso.

Es probable (o casi seguro) que no se descubra nada nuevo en este terreno. Pero el interés por plantear esa tarea no deviene del deseo por efectuar un descubrimiento revelador, totalmente original (¿aspiración máxima de todo científico?), sino de evaluar cómo un enfoque teórico en particular puede contribuir con el estudio de lo ya existente, es decir, temas que ya son problema de distintas disciplinas, en este caso en el ámbito de las Ciencias Sociales.

\section{Delimitación y especificidad de las metáforas}

Ya se ha dicho que la metáfora pertenece al mundo de las figuras retóricas, donde al igual que muchas de ellas (sinécdoques, metonimias - con las cuales forma un grupo de figuras también conocidas como tropos de la lengua), se define más por la forma en que establece la relación entre los objetos a los cuales se aplica, que por una formulación sintáctica específica.

Es decir, la lengua no constituye la única forma de expresar una metáfora. Y quizás en esto radique una de las diferencias con las alegorías, que son construcciones cercanas a las metáforas por su carácter representativo y simbólico, y tienen lugar principalmente en el campo de lo visual. En un primer intento por diferenciarlas podríamos decir que la alegoría no transgrede "ontológicamente", o lo hace en menor medida, las propiedades de los objetos con los que se elabora. Por ejemplo, el cuerno colmado de frutos y espigas como alegoría de la abundancia da cuenta de manera más transparente de su sentido $^{20}$ (siendo su propia transposición verbal es como tal una metáfora).

Sin embargo, es necesario establecer algunas precisiones o diferencias. Vamos a establecer, que las metáforas consisten en hacer inteligible algo en términos de otra $\operatorname{cosa}^{21}$, poniendo en relación (al menos) dos elementos que pertenecen a distintos órdenes de lo real. Las propiedades de esos elementos son atribuidas a otros, para dar cuerpo a una idea que no presenta dichos

${ }^{20}$ El antropólogo argentino Fernando Schwarz señala al respecto: “(...) en la alegoría el significante no es arbitrario, porque está obligado a ilustrar el significado en una forma convencional. Tiene que entrar en una coherencia de tal modo que uno se pueda dar cuenta de lo que se trata. Puede ser un elemento, una parte de lo que se quiere representar" $(2008,101)$. El carácter visual de la alegoría queda en claro en la siguiente definición: "Ilustración de conceptos y contenidos abstractos por medio de un objeto que tiene cierta relación real, convencional o simbólica, normalmente a través de personificaciones o de situaciones escénicas" (Stukenbrock y Töper, 2014, 978).

${ }^{21}$ Resulta clara en este punto la definición de Lakoff y Johnson: "The essence of metaphor is understanding and experiencing one kind of thing in terms of another" $(1980,125)$. La idea de "experimentar" las metáforas sin dudas agrega un componente de involucramiento psíquico y emocional a tener en cuenta. 
atributos, porque son incompatibles desde el punto de vista de su materialidad como objetos o seres, pero que es posible asimilar desde una perspectiva cultural concreta. Por ejemplo, en la Ilíada de Homero (2006) ${ }^{22}$ se lee repetidamente la expresión "la aurora de rosáceos dedos", que alude a la suave luminosidad del momento que precede al amanecer: de hecho los griegos no creían que este momento del día tuviera dedos, pero esa atribución (en la cual se transfiere parte de la anatomía humana a un fenómeno astronómico) es muy solidaria de un pueblo en el que la naturaleza solía estar personificada en un sinnúmero de deidades y que expresa muy bien la idea de una mano femenina que hace visibles las cosas al contacto de la luz sonrosada.

Por otra parte, a diferencia del mito, la metáfora no cuenta una historia, no supone una secuencia de hechos, sino que se resuelve como una síntesis en el momento que es utilizada, y el tiempo como tal no es un elemento que en realidad no reviste importancia en su dinámica constructiva interna. Los mitos son inseparables de la acción y la idea de causas y consecuencias, porque aparecen como resultado del comportamiento (deliberado o no) de alguien o incluso de objetos inanimados ${ }^{23}$. De alguna manera, en ello radica el misterio y la estupefacción de las metáforas, en las que el proceso cultural que las ha sedimentado no se da a entender en términos narrativos, sino directamente a través de un resultado, que las más de las veces es un breve sintagma.

Acepto, aunque parcialmente, la idea de que "la metáfora actúa así contra los principios de identidad y no contradicción” (Lizcano, 2006, p.61), lo cual las hace particularmente dúctiles a la imaginación social, aunque cabe la reserva de que los términos que se relacionan en ella no establecen el vínculo metafórico de manera totalmente arbitraria. (Este aserto será ilustrado con el análisis de las metáforas que se analizarán posteriormente.)

Estos últimos comentarios son propicios para mencionar el conocido parentesco entre la metáfora y la comparación. Aquella se ha explicado hasta el presente como una suerte de "comparación tácita". Al ser ambas en gran parte una creación colectiva, poseen algún fundamento que les da una

${ }^{22}$ Así, por ejemplo, en una arenga que dirige Diomedes a Agamenón, se lee "En cuanto aparezca la Aurora, de rosados dedos, / forma en seguida ante las naves a la hueste y los caballos, / aréngalos, y tú mismo lucha entre los primeros" (Ilíada IX, 707-709). Resulta de interés en este contexto mencionar la cita que Aristóteles hace de esta misma metáfora en su Retórica (2005): 1405 b, sin hacer referencia a ningún poeta o autor en particular, es decir, como metáfora "pública".

${ }^{23}$ Fernando Schwarz comenta respecto de los aspectos señalados: "El mito no puede trasmitirse más que por el verbo, es decir, de boca en boca; es la expresión del verbo creador. Expresa siempre el origen de algo, de cómo vinieron a la existencia el cosmos, el hombre, etc.; remite a un tiempo primordial, al cual se refiere sin cesar como la matriz de todos los tiempos presentes. En el mito los nombres de los dioses ocupan el lugar de los conceptos" (Schwarz, 2008, 80). 
configuración singular, al relacionar objetos que poseen algún atributo similar, aunque precisamente no se derive de su materialidad o subjetividad.

\section{Propuestas interpretativas}

En el terreno de la historia política de las sociedades latinoamericanas, ha sido muy frecuente, en particular en los períodos de organización de los estados como repúblicas, la selección de figuras relevantes del pasado en tanto que artífices de la libertad y soberanía de estos países. Los "padres de la patria", cuyas estatuas ecuestres suelen verse en las plazas de varias ciudades, fueron el resultado de esa "construcción" que es analizable desde la perspectiva de las metáforas, pero es importante aclarar que no se trata de construcciones simplemente inventadas desde un hipotético cero cultural. Una metáfora puede ser elaborada (en este caso, desde el poder político) de manera totalmente deliberada, pero su vigencia, y en algunos casos su permanencia en el mundo social, están garantizadas solamente si es capaz de impregnar la memoria de una comunidad.

Apenas planteado un caso muy conocido y en sus aspectos más elementales un ejemplo de metáfora como el anterior ("padre/s de la patria"), nos encontramos con que en realidad estas imágenes se superponen $o$ combinan con otras más universales o que no son en absoluto extrañas en otros medios culturales, con atributos significativos también muy similares a los que nosotros podemos asignarles. La imagen del padre incorporó también la del héroe arquetípico y podría decirse que es más afín aún a la de los caballeros medievales, ambos quizá más legendarios que reales.

En ese sentido, el caballero andante aporta elementos muy asociados al altruismo desinteresado de los próceres: el idealismo, el caballo y la espada. El carácter militar de estos héroes es, por su parte, evidente, y se entiende que los padres de la patria fueron capaces de consumar hazañas bélicas en estas tierras. Pero una vez más, conviene destacar la singularidad de los contextos culturales en los cuales las metáforas cobran vida: el Cid Campeador nunca habría podido convertirse en "padre de la patria española"...

La imagen de los padres fundadores, siempre en carácter de progenitor de una institución o un orden político determinado, de artífice que da paso a una entidad políticamente organizada que continúa hasta el presente, se halla presente también en otros ámbitos culturales. Por ejemplo, en los Estados Unidos, la metáfora refiere a personalidades históricas que participaron en la guerra de independencia (al igual que en el caso latinoamericano), aunque probablemente la imagen se corresponda mejor con su papel de firmantes del documento que declaró la independencia y con la constitución. En Europa se encuentra al menos un ejemplo muy ilustrativo en el caso de Vittorio Emanuele II, en cuya tumba en el Panteón de Roma se puede leer la misma expresión "padre de la patria". En el catolicismo también existe una versión 
de la metáfora de la paternidad (los padres de la Iglesia), reservada a un pequeño grupo de figuras santos que definieron lo sustancial de la doctrina en los primeros siglos de la era cristiana.

En el caso de nuestro país (Argentina), que cuenta con un padre de la patria indiscutido, se han superpuesto otras creaciones metafóricas. Una de ellas, que ha hecho bastante mella en el imaginario social, es la de "santo de la espada", y constituye un caso evidente de metaforización deliberada, es decir, aquella que presentan uno o más autores conocidos, como no es infrecuente en el terreno de las metáforas políticas.

La de santo de la espada, surgida en el seno de la corriente nacionalista, neutraliza la siempre sospechada condición de masón de nuestro padre patrio, y hace converger en él dos componentes de la sociedad colonial, que alude a las doble raíz del movimiento colonizador hispánico: la religión y las armas con las que se efectuó y consolidó la conquista. La apelación a la santidad, a la condición de santo patrio y civil, importa desde el mundo de la ascesis cristiana o, más específicamente, católica, un elemento fundamental: la virtud, que es el elemento no puesto en evidencia pero que permite conectar el mundo de la religión con el militar $^{24}$. Pero a diferencia del príncipe renacentista de Maquiavelo, no busca fundar un estado para ejercer un autogobierno legitimado por la conquista, sino ganar la libertad no solo para su patria natal, sino también para otros pueblos hispanoamericanos ${ }^{25}$

En ese sentido, la metáfora del santo de la espada no se desentiende de los atributos resaltados en relación a José de San Martín como cúspide del procerato argentino, elaborada por la corriente liberal clásica. El espíritu de sacrificio, el idealismo, la humildad y la idea de una misión emancipadora, se presentan como las propiedades que mediante el régimen de transposición de sentido que articulan las metáforas, confieren al padre de la patria una investidura transcendental y al mismo tiempo profundamente humana, al tiempo que le otorgan el carácter arquetípico implícito en la figura de los santos, los cuales son modelos a imitar o a seguir según el catecismo de la Iglesia, cuyos símiles en este caso no son otros que la conducta cívica y patriótica del ciudadano argentino. La capilla en la que descansan sus restos en la catedral primada de Buenos Aires, en un féretro muy elevado y debajo de una cúpula circular, terminan por completar esta suerte de apoteosis del héroe argentino.

${ }^{24}$ Sobre el problema de la virtud en el contexto de la cultura y la teoría política son particularmente esclarecedoras las consideraciones de Quentin Skinner, en el capítulo IV de As fundações do pensamento politico moderno (1996).

${ }^{25}$ Empresa ésta en la que aparece históricamente asociado al libertador Simón Bolívar (17831830). Los datos esenciales para entender el proceso de la gesta sanmartiniana se hallan bien reseñados en Historia contemporánea de América Latina, de Tulio Halperín Donghi (1986). 
Vale agregar, aunque más no sea de pasada, que la espada por sí misma ha dado lugar a una sorprendente variedad de metáforas. Se trata de un símbolo de poder que pone en evidencia la capacidad de ciertos objetos para asumir significados diferentes y hasta contradictorios. Está en la mano del Leviatán como alegoría de orden público en la ilustración de la cubierta de la primera edición del libro de Hobbes; el sector más tradicional de la nobleza francesa era noblesse de l'epée; Lugones habló, en el centenario de la batalla de Ayacucho, de la "hora de la espada" que debía llegar para el bien de la patria; en su representación alegórica más conocida, la justicia aparece sosteniendo una espada, etc.

En síntesis, y reduciéndolas a sus términos nucleares, lo que nos ofrecen las metáforas comentadas es una interpretación de un personaje histórico en términos de paternidad por un lado y santidad por otro.

Existen en nuestra historia política otras que han calado hondo, llegando a asumir incluso la forma de verdaderos epítetos. Por ejemplo: Eva, jefa espiritual de la nación; o: Evita, abanderada de los humildes. Detengámonos en la primera.

A diferencia de la anterior, que constaba de dos términos (padre y patria), ésta consta de tres: jefa, espíritu, nación. Estas nociones no dejan dudas sobre el talante político de la metáfora, en la que se ve resaltado el aspecto del mando y la autoridad en una relación de poder existente. Sin embargo, se trata de una jefa espiritual, cuya principalía no se realiza en la esfera más directa y concreta del poder, es decir, con un cargo en la estructura del gobierno, lo cual conferiría un cariz institucional y administrativo más corriente, y de hecho más alejado de la cercanía directa con el pueblo. Sin embargo esta condición no formal desde el punto de vista político (es decir, carente de un cargo estatal), lejos de menoscabar su capacidad para el logro de beneficios concretos para los interesados, la incrementaba, reforzando su cualidad carismática, en lo cual tuvo también mucho que ver el sistema de comunicación oficial.

Esta metáfora, complementada por otras igualmente eficaces como "hada buena" de los humildes y "abanderada de los trabajadores" (Halperin Donghi, 1986, p. 354), parece también hacerse eco de una representación de género vigente en su época, en la cual el mundo del espíritu pertenecía más a la mujer que al hombre. Esta idea se entiende mejor en la relación de complementariedad que ella tenía con respecto a su marido, complementariedad no equivalencial, sino que le asignaba un rango menor: ya que no podía ocupar o desempeñar el poder "formalmente" (como parte del Poder Ejecutivo), era regente de la vida espiritual de los argentinos, no como guía o conductora, sino como jefa. Esta no deja de ser una interpretación posible, si bien en la práctica no tuviera un papel tan contemplativo o escasamente influyente desde el punto de vista de las decisiones políticas. 
Por otra parte, no deja de merecer una mención el que la metáfora aluda a un colectivo humano como la nación, siendo que el movimiento político en el cual tuvo origen mostró una marcada predilección por el de pueblo, el cual identificaba mejor los destinatarios de su proyecto y su postura ideológica. Deliberadamente o no, es probable que se haya cristalizado la idea de nación justamente porque se desentiende mejor que pueblo de la heterogeneidad de clase y cultura a la que refiere la de pueblo.

Finalmente, podría entreverse entre los entresijos de esta construcción metafórica un indicio de la frágil cultura institucional del país, en la cual la acción del Estado se percibe a través de figuras concretas (lo cual la expone al riesgo de la discrecionalidad personal) y no como políticas públicas regidas por el criterio general y abstracto (pero también más racional) de la ciudadanía.

En los ejemplos anteriores nos referíamos a metáforas cuyos referentes son figuras históricas, pero esta aproximación al universo de las metáforas no estaría completa sin mencionar o al menos dejar establecida la existencia de una innumerable cantidad de metáforas que se aplican a otros aspectos de la realidad. Como aquí interesan en particular las que presentan un relieve político, comentaré algunas que responden más a esa característica.

La metáfora derecha-izquierda es tan corriente en el lenguaje político que no siempre tenemos en cuenta esa condición. Rehabilitada luego de la supuesta "muerte de las ideologías", supone la organización del espacio político a la manera de un espectro y permite ubicar personas e ideas según su orientación política. Mantuvo su vigencia en el mundo occidental desde el hecho totalmente anecdótico que le dio origen durante la Revolución Francesa. La ciencia política cuenta con otras metáforas espaciales que resultan menos problemáticas, también basadas en la idea abstracta de un espacio o universo político $^{26}$. Las relaciones horizontales de poder aluden naturalmente a relaciones políticas democráticas e igualitarias, mientras que las verticales ponen de hecho el acento en la autoridad y el mando ${ }^{27}$. En estos dos últimos casos no hay ninguna trasgresión de los términos que las expresan y son deductibles por ellos, pero ese no es el caso de derecha e izquierda. Es cierto

\footnotetext{
${ }^{26}$ Revalidando la vigencia de la díada derecha - izquierda, y rebatiendo la idea de crisis de las ideologías (muy en boga en la década de 1990), Bobbio escribe: “(...) izquierda y derecha no implican solamente ideologías. Reducirlas a la pura expresión de pensamiento ideológico sería una injusta simplificación: indican programas contrapuestos respecto a muchos problemas cuya solución pertenece habitualmente a la acción política, contrastes no solo de ideas, sino también de intereses y de valoraciones sobre la dirección que habría que dar a la sociedad, contrastes que existen en toda sociedad, y que no parece que vayan a desaparecer" $(2014,36)$

${ }^{27}$ Esta idea se halla bien desarrollada en un libro de Giovanni Sartori, Elementos de Teoría Política (1992), en el cual desarrolla, en el capítulo "Política", la idea de ajenidad de las relaciones verticales de autoridad en el discurso griego, su traducción latina y posterior desarrollo medieval.
} 
que lo izquierdo ha tenido desde antiguo connotaciones negativas mientras que lo derecho se asoció a lo correcto, lo lícito (e incluso a lo santo: "estar a la derecha de Dios" es signo de privilegio celestial ${ }^{28}$ ). Cada ha ubicado ideologías y partidos según estos criterios, atenuados por la inclusión de un "centro" que evitaría la radicalidad de los términos extremos.

Más relacionada con la idea de su funcionamiento y jerarquía, el organicismo es otra metáfora de peso en la historia de las formas de gobierno y las concepciones de la sociedad. Según Bobbio (1986) esta metáfora supone que el todo está primero que las partes, y predominó en la concepción de la sociedad en la Antigüedad y durante la Edad Media. La idea de "cuerpo místico", tan brillantemente explicada por San Pablo en le Primera Epístola a los Corintios, es bastante similar, aunque trascendiendo lo meramente terrenal. La democracia moderna, retomando a Bobbio, nació de una concepción individualista de la sociedad, que supuso naturalmente la disolución de la metáfora organicista. Ésta también ha calado en ámbitos castrenses, cristalizada en la famosa expresión "espíritu de cuerpo", que exige la acomodación de las acciones de cada miembro (generalmente entendido en términos de sacrificio o autopostergación) en pro del bien del grupo.

\section{Consideraciones finales}

La creación de metáforas que, como se puede inferir por lo consignado en este ensayo, se presenta indudablemente sostenida en el tiempo y en todos los ámbitos de la realidad social, debe llamarnos la atención y hacernos preguntar a qué deben esa eficacia que les asegura su continuidad como medio para expresar los más diversos sustratos culturales.

Insertas en el lenguaje, son un elemento vivo de la comunicación y forman parte de los recursos por medio de las cuales pensamos y damos cuenta de la realidad, por lo cual llevan la marca cosmovisional de las comunidades que las producen. Ilustran el universo valorativo, las asociaciones entre el mundo de los humanos y la naturaleza, las propiedades asignadas a los objetos, etc., que se transfieren a alguien o algo que no las posee como tales por sí mismo. De esta forma, sin duda contribuyen a revelar aspectos más soterrados, menos públicos, pero que sin duda informan acerca del imaginario social.

En materia de política la diversidad de metáforas es casi inagotable. Atañen al la concepción de la política como espacio, a la forma en que está compuesta la sociedad política, a los dirigentes, a los programas de gobierno, etc. Sin duda, proporcionan información de interés para los estudios de la

\footnotetext{
${ }^{28}$ Son numerosos los pasajes de las escrituras, y en oraciones (como el Credo) en los cuales aparece la idea de que estar a la diestra del Padre es signo de bienaventuranza, predilección y, en el caso de Cristo, un atributo de su divinidad. Así en uno de los Evangelios sinópticos se lee: "Con esto, el Señor Jesús, después de hablarles, fue elevado al cielo y se sentó a la diestra de Dios" (Mc 16, 19).
} 
cultura política, en la medida que revela las asociaciones y representaciones de los participantes del universo político en su elaboración, para aplicarlas a casos específicos que tienen lugar en su espacio y tiempo públicos.

En ese último sentido nos revelan las preocupaciones e incluso el sustrato ideológico que impregna el discurso, la formación de imágenes y las prácticas de políticos y ciudadanos en un momento dado, o en relación con un proyecto político de mayor alcance.

Conocerlas, o mejor dicho estudiarlas de manera analítica, abre el camino a descubrir el otro lado (o al menos uno de ellos) de las palabras y expresiones con las que acostumbramos hablar del mundo.

\section{References:}

1. Aime, M. 2015. Cultura. Buenos Aires: Adriana Hidalgo editora.

2. Aristóteles. 2005. El arte de la retórica. Buenos Aires: Eudeba.

3. Bachelard, G. 2013. La formación del espíritu científico. Contribución a un psicoanálisis del conocimiento objetivo. México: Siglo XXI.

4. Biblia de Jerusalén. 1998. Desclée de Brouwer: Bilbao.

5. Bobbio, N. 2014. Derecha e izquierda. Madrid: Taurus.

6. 1986. El futuro de la democracia. México: Fondo de Cultura Económica.

7. Halperin Donghi, T. 1986. Historia contemporánea de America Latina. Buenos Aires: Alianza Editorial.

8. Homero, 2006. Ilíada. Barcelona: Gredos.

9. Lakoff, G. \& Mark Johnson, M. (1980). Metaphors we live by. Chicago: University of Chicago Press. Acceso el 21 de Julio de 2017: http://www.cc.gatech.edu/classes/AY2013/cs7601_spring/papers/Lak off_Johnson.p

10. Lizcano, E. (2006). Metáforas que nos piensan. Sobre ciencia, democracia y otras poderosas ficciones. Madrid: Ediciones Bajo Cero / Traficante de sueños.

11. Acceso el 21 de julio 2017: https://www.traficantes.net/sites/default/files/pdfs/Metaforas\%20que $\% 20$ nos\%20piensan-TdS.pdf

12. Sartori, G. 1992. Elementos de Teoría Política. Buenos Aires: Alianza.

13. Schwarz, F. 2008. Mitos, ritos, símbolos. Antropologías de lo sagrado. Buenos Aires: Editorial Biblos.

14. Skinner, Q. 1996. As fundações do pensamento politico moderno. São Paulo: Companhia das Letras.

15. Stukenbrock, Ch. \&. Töper, B. 2014. 1000 obras maestras de la pintura. Postdam: H. F. Ullmann publishing Gmbh. 